Research Article

\title{
Enhancement in Optical Properties of Lanthanum-Doped Manganese Barium Hexaferrites under Different Substitutions
}

\author{
Meshal Alzaid \\ Physics Department, College of Science, Jouf University, P.O. Box 2014, Sakaka, Al-Jouf, Saudi Arabia \\ Correspondence should be addressed to Meshal Alzaid; mmalzaid@ju.edu.sa
}

Received 22 September 2020; Accepted 3 February 2021; Published 8 March 2021

Academic Editor: Sefer Bora Lisesivdin

Copyright (c) 2021 Meshal Alzaid. This is an open access article distributed under the Creative Commons Attribution License, which permits unrestricted use, distribution, and reproduction in any medium, provided the original work is properly cited.

\begin{abstract}
The permeability and electrical resistivity of barium hexaferrite magnetic materials can be used in various products such as magnetic recording media, computers, electronic devices, materials for permanent magnets, and communication devices. This work focuses on the synthesis of rare earth lanthanum $\left(\mathrm{La}^{3+}\right)$-doped manganese in barium hexaferrite $\left(\mathrm{Ba}_{1-x} \mathrm{La}_{x} \mathrm{Mn}_{y} \mathrm{Fe}_{12-y} \mathrm{O}_{19}\right)$ $(x=0.02-0.10$ and $y=0.02-0.10)$ prepared by using the coprecipitation method. The intensity peak is increased with increasing the concentration of lanthanum, which shows the enhancement in the degree of crystallinity and increase in the size of crystallite. The band gap energy decreased gradually with the increase of concentration of lanthanum. The micrographs observed that the material is basically made up of some rings or rods such as particles in pure La-Ma in barium hexaferrite. The agglomeration was observed because of heat behavior at $600^{\circ} \mathrm{C}$ or may be concentration effect. The structural studies are done using X-ray diffraction, UV, FTIR, and SEM techniques.
\end{abstract}

\section{Introduction}

The barium hexaferrite $\left(\mathrm{BaFe}_{12} \mathrm{O}_{19}\right)$ has been widely used as permanent magnetic materials. The microwave-absorbing materials have been used in military and the civil technology, such as garnet and spinel ferrites [1]. The permeability and electrical resistivity barium hexaferrite magnetic materials can be used in various products such as magnetic recording media, computers, electronic devices, materials for permanent magnets, and communication devices $[2,3]$. The barium hexaferrite is very important for industrial use. The nanoparticles of barium hexaferrite have large saturation magnetization, high electrical resistivity, large uniaxial magnetic anisotropy, chemical strength, high curie temperature, and high coerciveness because their compounds can also be used at high frequency as correlated spinel ferrites and garnet $[4,5]$. The electromagnetic compatibility used for special sensitive equipment in the application of hexagonal ferrites and compounds is based on great possibility as materials for higher electromagnetic frequency [6]. There are some materials exist together between ferroelectric and ferromagnetism. To reform intrinsic magnetic properties of hexaferrites, it can be achieved by using various techniques including doping of La-Mn for Ba or Fe or both sublattices [7]. The barium hexaferrite is used in the fabrication of equipment and plays an important role in the improvement of technology and industrial products. Depending on magnetic behavior, the magnetic materials are categorized into ferromagnetic, diamagnetic, and paramagnetic materials. Ferrites made a cubic structure, but some ferrites made hexagonal crystal structure also known as hexaferrites [4]. The chemical composition and crystal structure of hexagonal ferrites have six types. These structures can be distinguished as Y-type $\left(\mathrm{Ba}_{2} \mathrm{Me}_{2} \mathrm{Fe}_{12} \mathrm{O}_{22}\right)$, W-type $\left(\mathrm{Ba}_{2} \mathrm{Me}_{2} \mathrm{Fe}_{12} \mathrm{O}_{22}\right), \mathrm{U}$-type $\left(\mathrm{Ba}_{4} \mathrm{Me}_{2} \mathrm{Fe}_{36} \mathrm{O}_{60}\right), \mathrm{X}$-type $\left(\mathrm{Ba}_{2} \mathrm{Me}_{2} \mathrm{Fe}_{28} \mathrm{O}_{46}\right)$, Z-type $\left(\mathrm{Ba}_{3} \mathrm{Me}_{2} \mathrm{Fe}_{24} \mathrm{O}_{41}\right)$, and M-type $\left(\mathrm{BaFe}_{12} \mathrm{O}_{19}\right)$ [8-10]. The unit cell of M-type hexaferrite contains 2 barium ions and 24 ferric and 38 oxygen ions. In the unit cell, the 24 ferric ions occupy five distinct sites, such as $2 \mathrm{a}, 2 \mathrm{~b}, 4 \mathrm{f}_{1}, 4 \mathrm{f}_{2}$, and $12 \mathrm{k}$. The crystal structure of $4 \mathrm{f} 1 \mathrm{is}$ tetrahedral, $2 \mathrm{~b}$-formed trigonal, and $12 \mathrm{k}, 2 \mathrm{a}$, and $4 \mathrm{f}_{2}$ are octahedral sites [11]. The substitution of ions at different positions in the crystal structure and magnetic moment depends on the electronic arrangement of the atoms [12]. 
The $\mathrm{Fe}^{3+}$ ions have their spins parallel to the crystallographic $\mathrm{c}$-axis in the $2 \mathrm{a}(\uparrow), 2 \mathrm{~b}(\uparrow)$, and $12 \mathrm{k}(\uparrow)$ sites, whereas $4 \mathrm{f}_{1}(\downarrow)$ and $4 f_{2}(\downarrow)$ sites have opposite direction. The sublattices ( $2 \mathrm{a}$, $2 \mathrm{~b}$, and $12 \mathrm{k})$ and $\left(4 \mathrm{f}_{1}\right.$ and $\left.4 \mathrm{f}_{2}\right)$ are parallel and antiparallel to the hexagonal c-axis [13]. Ferroelectric and ferromagnetism coexist in very few materials. The substitution of diamagnetic cations in barium hexaferrite has large spontaneous multiferric and magnetoelectric effect and polarization property at room temperature [6]. Keeping this in mind, we have designed this study to synthesize lanthanum manganese barium hexaferrite nanoparticles with different lanthanum precursor concentrations and studied its effect on the optical properties.

\section{Experimental Detail}

To synthesize the chemicals, iron nitrate monohydrate $\left(\mathrm{Fe}\left(\mathrm{NO}_{3}\right)_{3} \cdot 9 \mathrm{H}_{2} \mathrm{O}\right) 98 \%$, manganese chloride tetrahydrate $\left(\mathrm{MnCl}_{2} \cdot 4 \mathrm{H}_{2} \mathrm{O}\right)$ 99\%, lanthanum acetate $\left(\mathrm{La}\left(\mathrm{CH}_{3} \mathrm{CO}_{2}\right)_{3}\right)$ $99 \%$, barium chloride dehydrate $\left(\mathrm{BaCl}_{2} \cdot 2 \mathrm{H}_{2} \mathrm{O}\right) 97 \%$, and sodium hydroxide $(\mathrm{NaOH})$ 98\% were dissolved at stoichiometric quantities of chemicals in distilled water. All analytical grade samples used in the preparation of material were purchased from Merck and Sigma-Aldrich through local suppliers in pure form without any need of further purification.

The rare earth lanthanum $\left(\mathrm{La}^{3+}\right)$-doped manganese in barium hexaferrite $\left(\mathrm{Ba}_{1-x} \mathrm{La}_{x} \mathrm{Mn}_{y} \mathrm{Fe}_{12-y} \mathrm{O}_{19}\right) \quad(x=0.02-0.10$ and $y=0.02-0.10$ ) was prepared by using the coprecipitation method. The chemicals used for the preparation of the samples were iron nitrate monohydrate $\left(\mathrm{Fe}\left(\mathrm{NO}_{3}\right)_{3} \cdot 9 \mathrm{H}_{2} \mathrm{O}\right)$, manganese chloride tetrahydrate $\left(\mathrm{MnCl}_{2} \cdot 4 \mathrm{H}_{2} \mathrm{O}\right)$, lanthanum acetate $\left(\mathrm{La}\left(\mathrm{CH}_{3} \mathrm{CO}_{2}\right)_{3}\right)$, barium chloride dehydrate $\left(\mathrm{BaCl}_{2} \cdot 2 \mathrm{H}_{2} \mathrm{O}\right)$, and sodium hydroxide $(\mathrm{NaOH})$, and they were dissolved at stoichiometric quantities of chemicals in distilled water. The stoichiometric ratio was used to synthesize the $\left(\mathrm{Ba}_{1-x} \mathrm{La}_{x} \mathrm{Mn}_{y} \mathrm{Fe}_{12-y} \mathrm{O}_{19}\right)$ hexaferrites. The solution was mixed well and then stirred to obtain homogenous solution. The solution was mixed with precipitate agent $(\mathrm{NaOH})$ to obtain less chemically dispersion of nanoparticles and then further stirred at $100^{\circ} \mathrm{C}$ for 90 minutes to changing of hydroxide $\left(\mathrm{OH}^{-}\right)$into ferrites. During stirring, the addition of $\mathrm{NaOH}$ (drop wise) in solution helps to maintain the PH 12 throughout the reaction. As the stirring was stopped, the PH was approached at 12. After that, samples had kept for aging whole night. Once the reaction process completed, the precipitates present in the solution are settled down and ready to collect. To remove the impurities, collected precipitates were washed several times with distal water, and sodium and hydrogen ions are removed. The sample was places in an oven for 12 hours at $90^{\circ} \mathrm{C}$. The precipitates were grinded into clear powder form with pestle mortar and then sintered at $600^{\circ} \mathrm{C}$ in muffle furnace for 3 hours. Four samples with different lanthanum concentration have been prepared.

The flowchart of lanthanum $\left(\mathrm{La}^{3+}\right)$-doped manganese in barium hexaferrite $\left(\mathrm{Ba}_{1-x} \mathrm{La}_{x} \mathrm{Mn}_{y} \mathrm{Fe}_{12-y} \mathrm{O}_{19}\right)$ is shown in Figure 1.

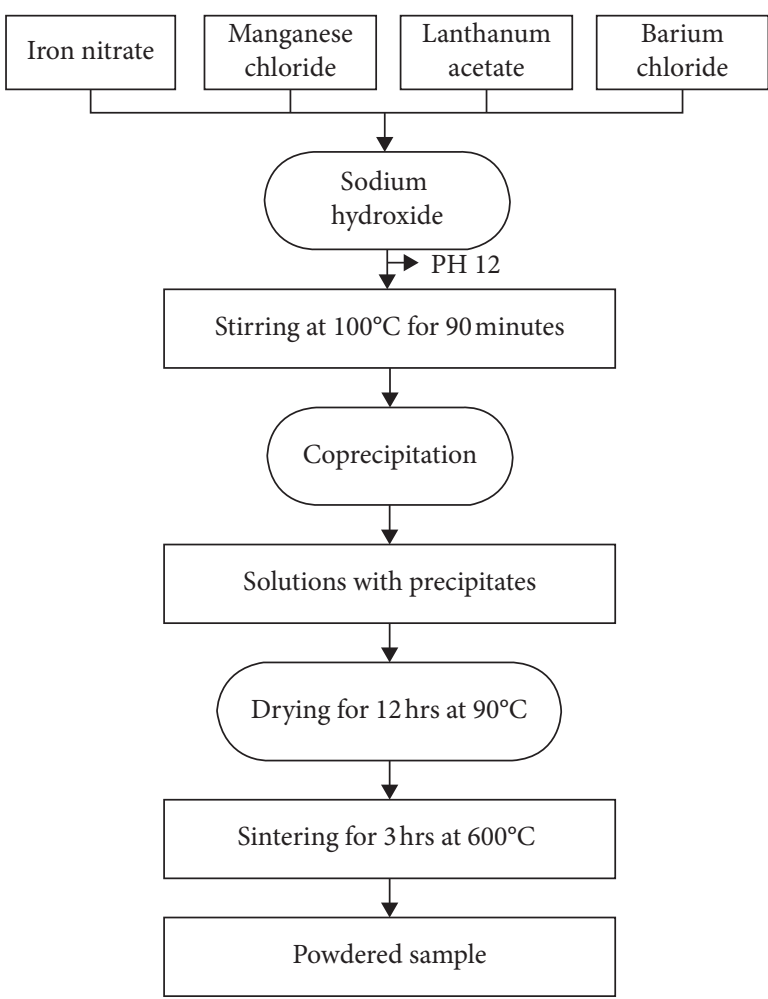

FIgURE 1: Flowchart of $\mathrm{Ba}_{1-x} \mathrm{La}_{x} \mathrm{Mn}_{y} \mathrm{Fe}_{12-y} \mathrm{O}_{19}$ hexaferrites.

\section{Result and Discussion}

All the samples were analyzed by XRD analysis. This is the most widely used diffraction method to determine the structure of crystalline solid when X-rays are diffracted not by single crystal but form randomly oriented crystalline particles. These peak patterns are used for the identification and measurement of different structural phases and parameters. The powder method is the very quick and convenient method to obtain diffraction data and readily applicable to all crystalline materials. The XRD analysis was performed with $\mathrm{Cu}-\mathrm{K} \alpha(1.5406 \AA)$ radiation at ambient temperature for the study of phase structure, lattice parameters, and crystallite size. The XRD pattern of lanthanumdoped manganese barium hexaferrite $\left(\mathrm{Ba}_{1-x} \mathrm{La}_{x} \mathrm{Mn}_{y} \mathrm{Fe}_{12-y} \mathrm{O}_{19}\right)$ is shown in Figure 2. The sharp peaks (012), (220), (114), (311), (210), (400), (217), (039), (411), and (132) are at angles 24.12, $30.22,34.20,35.50,40.62,42.36,49.61,57.13,63.24$, and 70.24 . The diffraction peaks were identified by using JCPDS card \# 731964 and \# 44-0206 of the hexagonal crystal structure. The X-ray diffraction of phase purity and crystal structure of $\mathrm{Ba}_{1-x} \mathrm{La}_{x} \mathrm{Mn}_{y} \mathrm{Fe}_{12-y} \mathrm{O}_{19}$ hexaferrite were prepared by the lanthanum substitutions.

The intensity peaks were changed due to the substitution of lanthanum-doped manganese hexaferrite in crystal structure. The sharp peak (311) moves towards a lower angle to the higher angle as shown in Figure 2. The peak (311) shifted towards a lower angle to the higher angle due to the larger ionic radii of $\mathrm{La}(2.35 \AA)$ and $\mathrm{Mn}(0.91 \AA)$ compared to hexaferrite ions. The lanthanum-doped manganese hexaferrite has hexagonal structure. 


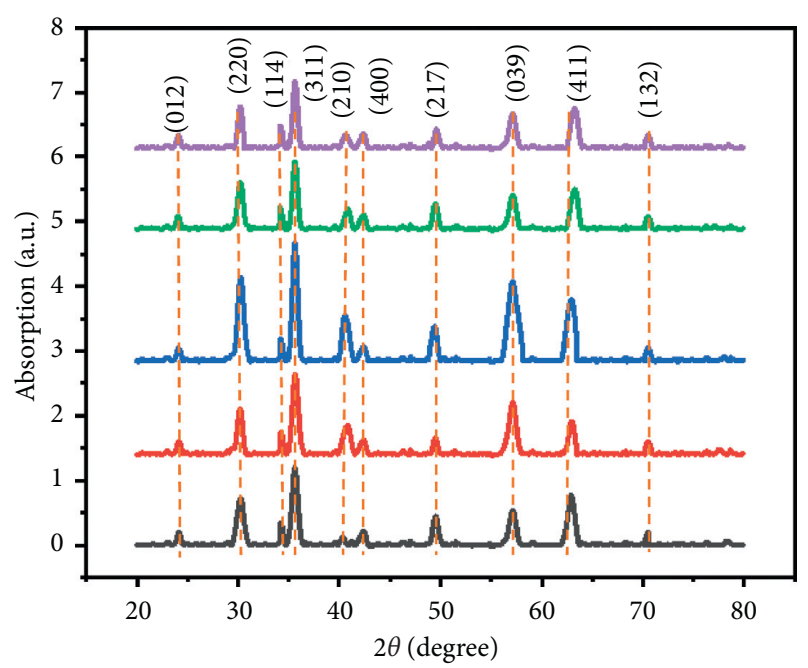

Figure 2: XRD pattern of $\left(\mathrm{Ba}_{1-x} \mathrm{La}_{x} \mathrm{Mn}_{y} \mathrm{Fe}_{12-y} \mathrm{O} 19\right) x=0.02$ to 0.10 and $y=0.2$ to 0.10 for hexaferrites.

The average crystalline size can be calculated from XRD by Scherrer's equation [14]:

$$
D=\frac{0.9 \lambda}{\beta \cos \theta},
$$

where " $D$ " is the crystalline size, " $\lambda$ " is the wavelength, " $\beta$ " is the full width at half maximum, and $\theta$ is Bragg's angle. The intensity peak is increased with increasing the concentration of lanthanum, which shows the enhancement in the degree of crystallinity and increase in the size of crystallite. The average sizes of the crystalline samples were determined from the width of peaks by using the Scherrer relation. The average crystalline size was found to be 13.10, 13.61, 14.80, 15.77, and $16.19 \mathrm{~nm}$, shown in Figure 3, for the samples prepared with a lanthanum concentration of $0.02,0.04$, 0.06 .0 .08 , and 0.10 mole, respectively. The value of crystalline size can be seen in Table 1 .

The lattice parameters " $a$ " and " $c$ " are calculated from the following relation:

$$
\frac{1}{d^{2}}=\frac{4}{3}\left(\frac{h^{2}+h k+l^{2}}{a^{2}}\right)+\frac{l^{2}}{c^{2}} .
$$

Here, $(h k l)$ are miller indices, " $d$ " is the interplanar spacing, and " $a$ " and " $c$ " are the lattice constant.

The volume of hexagonal structure can be determined from the following formula:

$$
V=\frac{\sqrt{ } 3}{2} a^{2} c,
$$

where " $V$ " is the volume and " $a$ " and " $c$ " are the lattice constant of hexaferrites.

UV-visible absorption and band gap energy of a material are energetic techniques to analyze the optical properties of semiconductor material. For the sample $\mathrm{Ba}_{1-x} \mathrm{La}_{x} \mathrm{Mn}_{y} \mathrm{Fe}_{12-y} \mathrm{O}_{19}$ ( $x=0.02$ to 0.08 and $y=0.2$ to 0.8 ), UV-visible absorption spectra of La-Mn hexaferrite are shown in Figure 4. Figure 4 shows the absorption spectrum

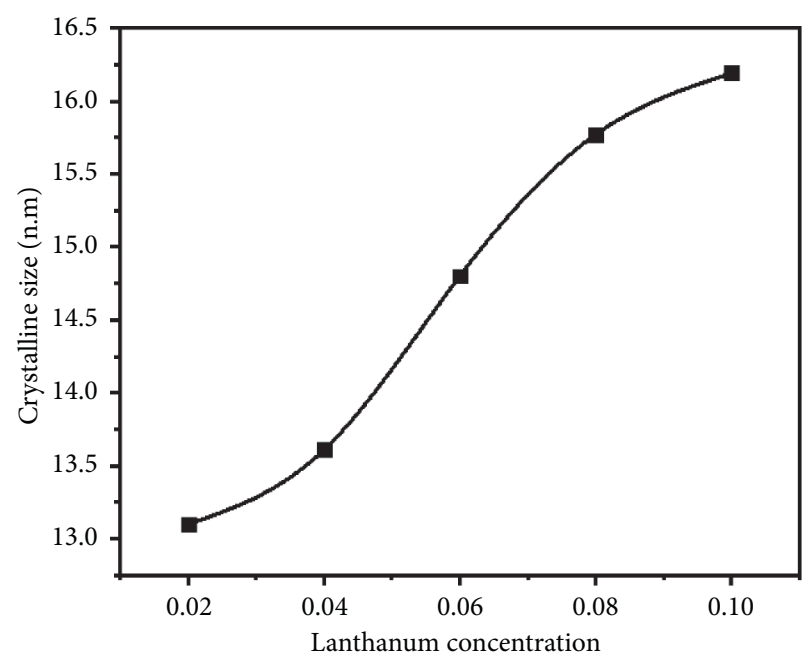

FIgURE 3: Lanthanum concentration and crystalline size of manganese barium hexaferrite.

\begin{tabular}{|c|c|c|c|c|}
\hline \multirow[t]{2}{*}{ Lanthanum contents $(x)$} & \multirow[t]{2}{*}{$D(\mathrm{~nm})$} & \multicolumn{2}{|c|}{$\begin{array}{c}\text { Lattice } \\
\text { constant }(\AA) \\
a=b \neq c\end{array}$} & \multirow[t]{2}{*}{ Volume } \\
\hline & & $a$ & $C$ & \\
\hline 0.02 & 13.10 & 2.318 & 1.008 & 4.690 \\
\hline 0.04 & 13.61 & 2.307 & 1.007 & 4.645 \\
\hline 0.06 & 14.80 & 2.317 & 1.0006 & 4.651 \\
\hline 0.08 & 15.77 & 2.316 & 1.0005 & 4.647 \\
\hline 0.10 & 16.19 & 2.319 & 1.0080 & 4.694 \\
\hline
\end{tabular}

TABLE 1: Lanthanum concentration, crystalline size, lattice constant, and volume of hexaferrites have been calculated.

of $\mathrm{Ba}_{1-x} \mathrm{La}_{x} \mathrm{Mn}_{y} \mathrm{Fe}_{12-y} \mathrm{O}_{19}$ wavelength between 300 and $900 \mathrm{~nm}$ in region. The absorbance sharply increases from 0.5 to 1 with the increases in wavelength from $360 \mathrm{~nm}$ to $500 \mathrm{~nm}$, and absorbance gradually increases from 1 to 1.15 as the wavelength increases from $500 \mathrm{~nm}$ to $900 \mathrm{~nm}$. This peak identifies the inner shell electron transition. There is a minor peak shifting on both sides towards lower and higher wavelengths which is responsible for the blue and red shifts, respectively. The tangent is drawn in a Tauc plot to find the energy gap which is $(1.13 \mathrm{eV}, 0.77 \mathrm{eV}, 0.74 \mathrm{eV}, 0.72 \mathrm{eV}$, and $0.71 \mathrm{eV}$ ) shown in Figure 4.

The band gap energies of the La-doped Mn hexaferrite sample are greater than the quixotic energy. By the Tauc plot mode, we determine the information between energy and $(\alpha h v)^{2}$ from UV-visible absorption.

The plotting of $(\alpha h \nu)^{2}$ vs the photon energy $(h \nu)$ gives a straight line in a certain region. The Tauc plot equation is

$$
\alpha h v=A(h v-E g)^{\gamma},
$$

where $A$ is an absorption constant, $E g$ is the band gap energy, and $h v$ is the photon energy. The $\gamma$ is the type of electronic transition which is $1 / 2,2,3 / 2$, and 3 . The $\gamma=1 / 2$ corresponds to direct band gap of semiconductor materials. This equation is used to calculate the band gap of theoretical energy: 

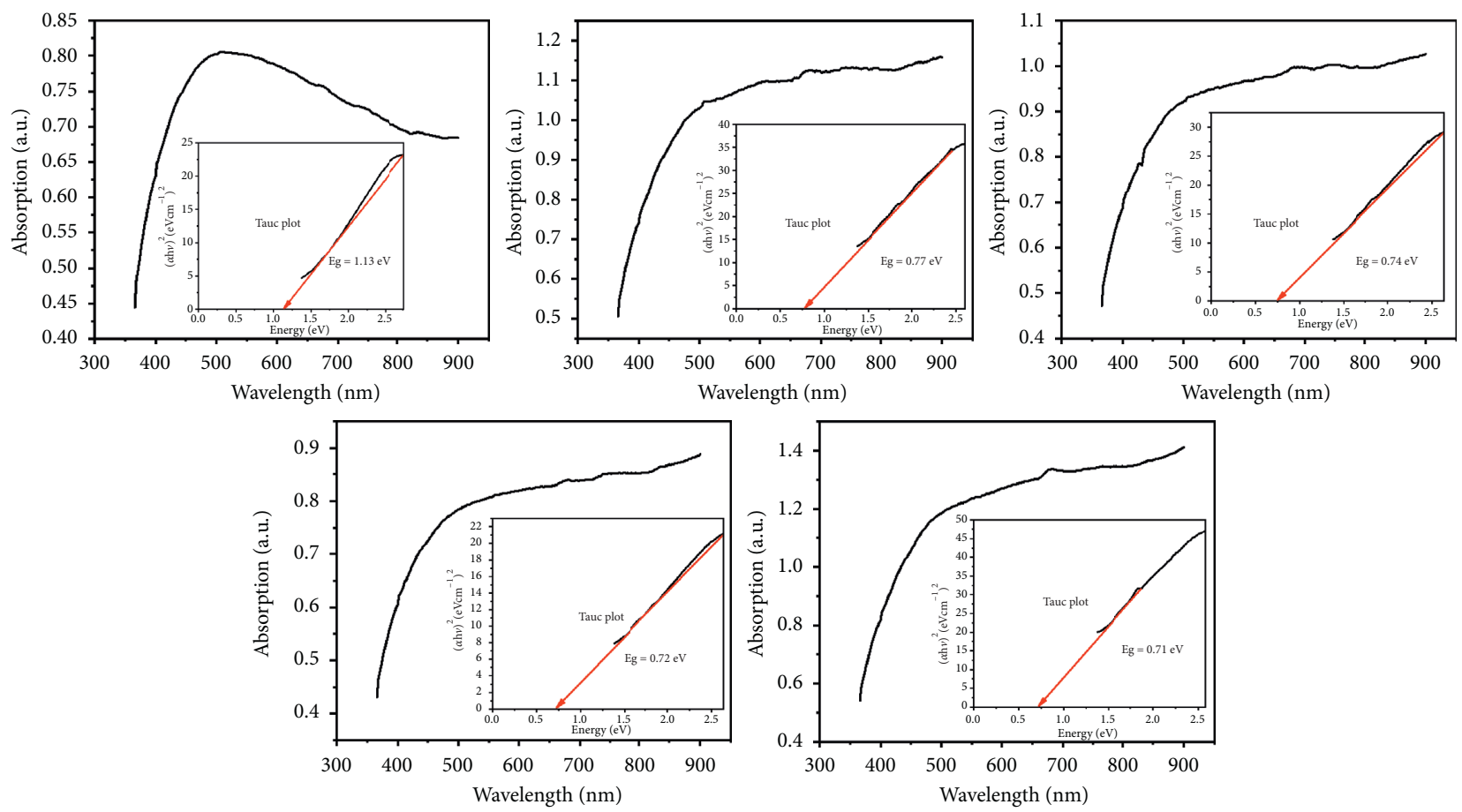

FIgURE 4: UV pattern of lanthanum-doped manganese barium hexaferrite $\mathrm{Ba}_{1-x} \mathrm{La}_{x} \mathrm{Mn}_{y} \mathrm{Fe}_{12-y} \mathrm{O}_{19}(x=0.02$ to 0.08 and $y=0.2$ to 0.8$)$.

$$
\alpha h v=A(h v-E g)^{1 / 2} .
$$

The calculation formula is

$$
\alpha=2.303\left(\frac{A b}{t}\right) .
$$

Here, $A b$ is the absorbance and $t$ is the thickness of the cuvette.

The band gap energy $(E g=1.13 \mathrm{eV}, 0.77 \mathrm{eV}, 0.74 \mathrm{eV}$, $0.72 \mathrm{eV}$, and $0.71 \mathrm{eV}$ ) is shown in Table 2, which decreases gradually with the increase of the sample $\mathrm{Ba}_{1 x} \mathrm{La}_{x} \mathrm{Mn}_{y} \mathrm{Fe}_{12-y} \mathrm{O}_{19}(x=0.02$ to 0.10 and $y=0.2$ to 0.10$)$ as shown in Figure 5 . The band width of conduction and valance bands decrease as the concentration of lanthanum is increased, which results reduced in band gap. In addition, the band gap values decrease with increases in lanthanum concentrations which means the energy levels within the bands are decreased in which each electron required more energy to jump from valance band to conduction band.

Scanning electron microscopy have been performed to study the microsrtrucural and surface properties of Ba1-xLaxMnyFe12-yO19 as shown in Figure 6. The shape of SEM images is irregular cubic, spiral, rings, and rods shown in Figure 6. The micrographs observed that the material is basically made up of some rings or rods such as particles in pure La-Ma in barium hexaferrite (Figure 6(a)), and as the concentration of the lanthanum increases, an increase also occurs in the agglomeration of these particles. The agglomeration was observed because of heat behavior at $600^{\circ} \mathrm{C}$ or may be concentration effect. Further vacancies of oxygen atom are created by introducing $\mathrm{La}$ at $\mathrm{Fe}^{+3}$ sites of barium ferrites. Rate of sintering significantly improves
TABLE 2: Concentration and binding energy of hexaferrites through the Tauc plot have been calculated.

\begin{tabular}{lcc}
\hline Samples & Contents $(X)$ & Binding energy \\
\hline S1 & 0.02 & 1.13 \\
S2 & 0.04 & 0.77 \\
S3 & 0.06 & 0.74 \\
S4 & 0.08 & 0.72 \\
S5 & 0.10 & 0.71 \\
\hline
\end{tabular}

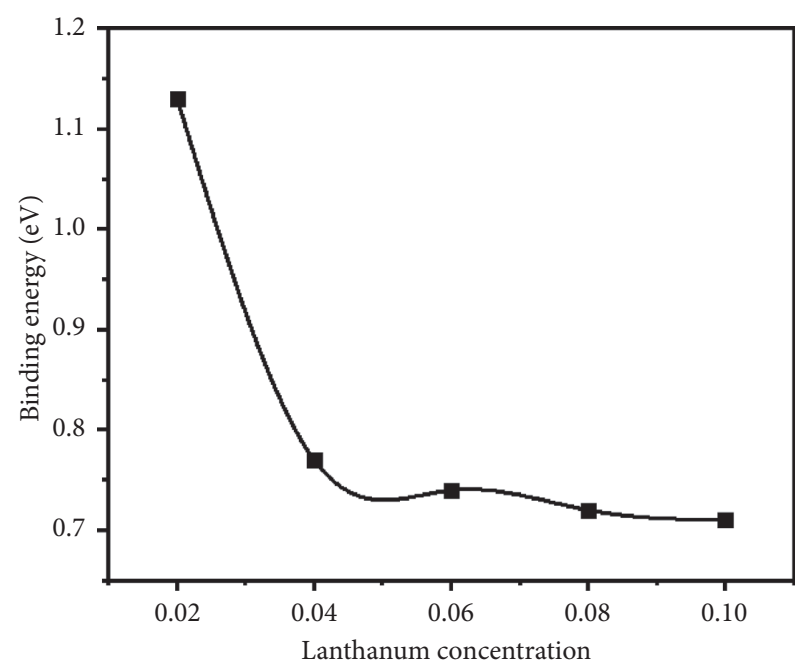

FIGURE 5: Lanthanum concentration and binding energy of manganese barium hexaferrite.

grain size of prepared samples. The cluster formation at higher concentration of lanthanum is due to swapping of paramagnetic and ferromagnetic behavior of lanthanum and 

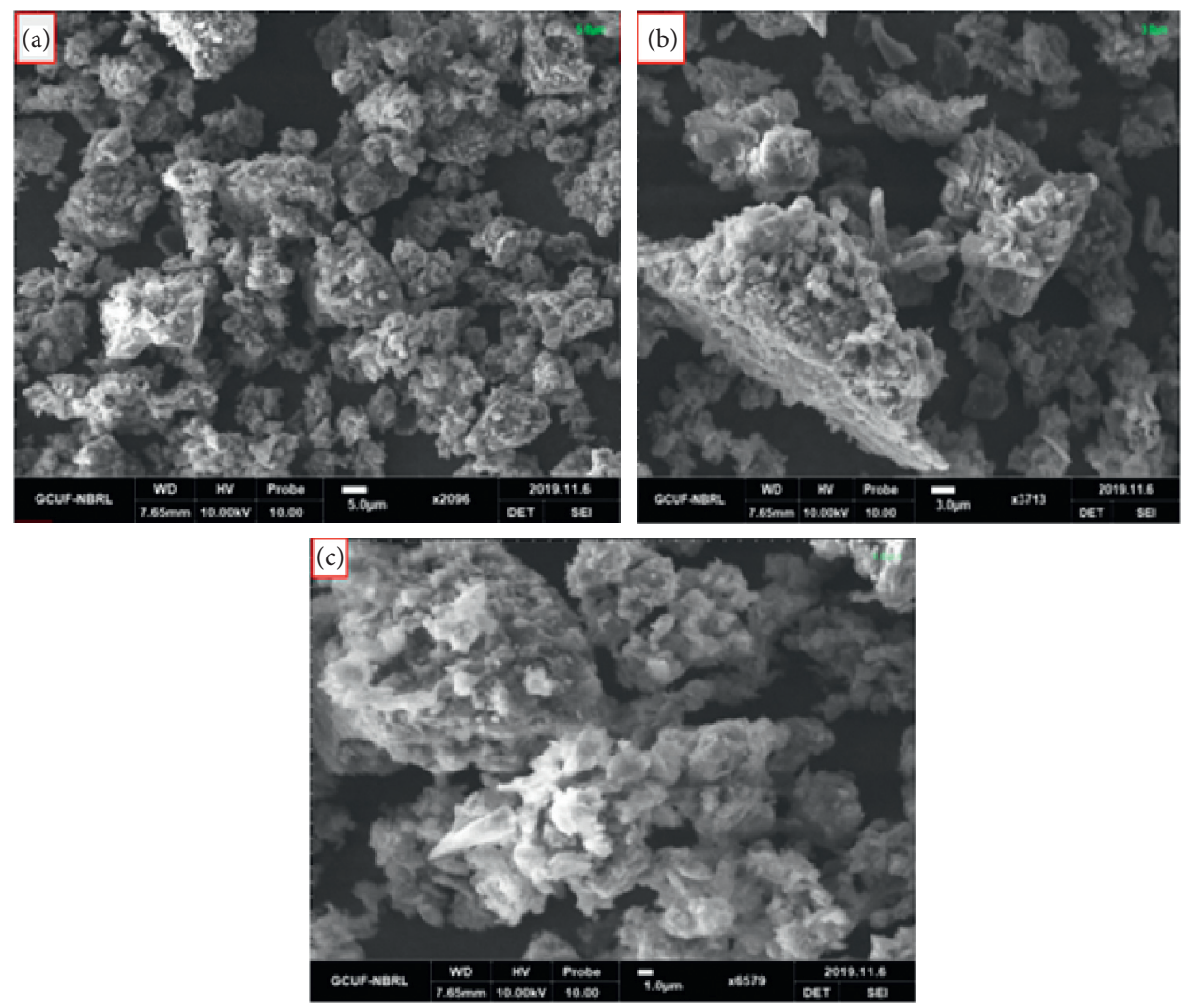

Figure 6: SEM pattern of $\left(\mathrm{Ba}_{1-x} \mathrm{La}_{x} \mathrm{Mn}_{y} \mathrm{Fe}_{12-y} \mathrm{O}_{19}\right) x=0.02$ to 0.08 and $y=0.2$ to 0.8 for hexaferrites.

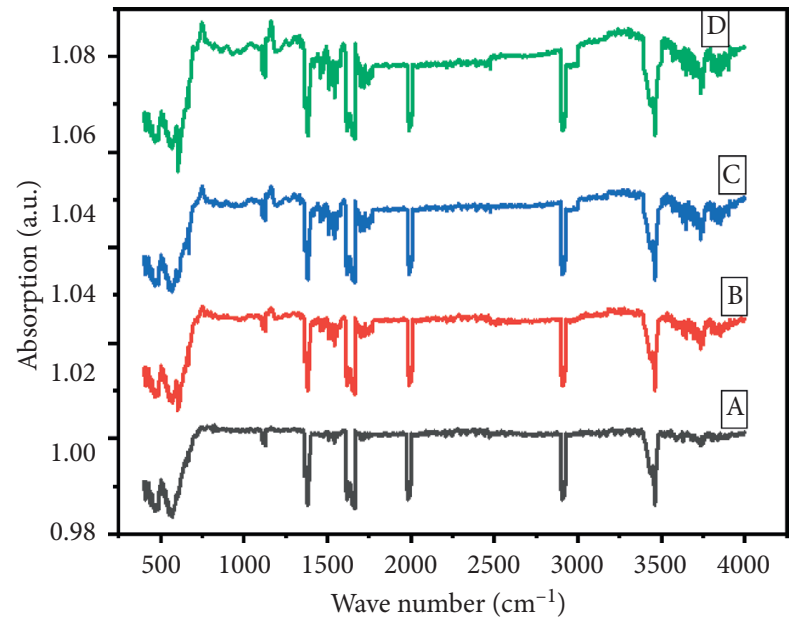

Figure 7: IR pattern of $\left(\mathrm{Ba}_{1-x} \mathrm{La}_{x} \mathrm{Mn}_{y} \mathrm{Fe}_{12-y} \mathrm{O}_{19}\right) x=0.02$ to 0.08 and $y=0.2$ to 0.8 for hexaferrites.

manganese, respectively. SEM images for all compositions represent nonuniform grain size distribution with sharp edges on its surface.

Fourier transform infrared (FT-IR) spectroscopy is an analysis used to generate an infrared radiation absorption spectrum of a material. The FT-IR analysis of $\mathrm{Ba}_{1-x} \mathrm{La}_{x} \mathrm{Mn}_{y} \mathrm{Fe}_{12-y} \mathrm{O}_{19} \quad(x=0.02-0.10$ and $y=0.2-0.10)$ hexagonal ferrite has been studied in the wave number ranges from 400 to $4000 \mathrm{~cm}^{-1}$, and it is shown in Figure 7 .
The FT-IR spectra of the samples were conducted to identify the organic polypyrrole (PPy) and inorganic lean body mass (LBM) elements present in the sample. The FT-IR spectrum peaks are $465 \mathrm{~cm}^{-1}, 610 \mathrm{~cm}^{-1}, 1128 \mathrm{~cm}^{-1}, \quad 1380 \mathrm{~cm}^{-1}$, $1628 \mathrm{~cm}^{-1}, 1988 \mathrm{~cm}^{-1}, 2920 \mathrm{~cm}^{-1}, 3458 \mathrm{~cm}^{-1}$, and $3735 \mathrm{~cm}^{-1}$ shown in Figure 7. The first band between 440 and $540 \mathrm{~cm}^{-1}$ attributed to vibration of $\mathrm{Fe}^{3+}-\mathrm{O}^{2-}$ at octahedral clusters, and the second band between 540 and $600 \mathrm{~cm}^{-1}$ is indicating the vibration of $\mathrm{Fe}^{3+}-\mathrm{O}^{2-}$ at tetrahedral clusters of crystallographic sites (9-10). Due to increase the concentration of lanthanum $\left(\mathrm{La}^{3+}\right)$, the absorption band gradually broadened and the frequency decreased with the increase of lanthanum content. FT-IR spectra of lanthanum-doped manganese barium hexaferrites demonstrate insignificant contamination quantity in the prepared samples of $\mathrm{Ba}_{1-x} \mathrm{La}_{x} \mathrm{Mn}_{y} \mathrm{Fe}_{12-y} \mathrm{O}_{19}$.

\section{Conclusion}

The La-Mn substituted barium hexaferrite with nominal composition $\mathrm{Ba}_{1-x} \mathrm{La}_{x} \mathrm{Mn}_{y} \mathrm{Fe}_{12-y} \mathrm{O}_{19} \quad(x=0.02-0.08$ and $y=0.2-0.8)$ has been successfully synthesized using the coprecipitation method. Magnetic properties of La-Mn substituted barium hexaferrites including large magnetic anisotropy, large saturation magnetization, high electrical resistivity, high curie temperature, and good chemical strength by the reason of these compounds can be used at higher frequency as correlated to garnet and spinel ferrites. The structural studies are done using XRD, UV, FT-IR, and 
SEM techniques. XRD analysis shows pure hexagonal structure. The Scherrer formula was used to calculate the crystalline size of magnetic material. The average crystallite size for the calcined sample was in the range of 13-22 nm. Absorbance of the sample was measured by UV spectroscopy. The energy band gap decreases gradually with the increase of sample concentration. The band width of conduction and valance bands decrease as the concentration of lanthanum is increased, which results reduced in band gap. SEM micrograph images for all compositions represent nonuniform grain size distribution with sharp edges on its surface. The agglomeration has been observed due to heat treatment at $600^{\circ} \mathrm{C}$ or may be concentration effect. The micrographs observed that the material is basically made up of some rings or rods such as particles in pure La-Ma in barium hexaferrite (Figure 6(a)), and as the concentration of the lanthanum increases, an increase also occurs in the agglomeration of these particles. The FT-IR spectra of the samples were conducted to identify the organic polypyrrole (PPy) and inorganic lean body mass (LBM) elements present in the sample.

\section{Data Availability}

The XRD, SEM, FT-IR, and UV data used to support the findings of this study are included within the article.

\section{Conflicts of Interest}

The authors declare that they have no conflicts of interest.

\section{References}

[1] M. Ahmad, F. Aen, M. U. Islam, S. B. Niazi, and M. U. Rana, "Structural, physical, magnetic and electrical properties of Lasubstituted W-type hexagonal ferrites," Ceramics International, vol. 37, no. 8, pp. 3691-3696, 2011.

[2] K. K. Kefeni, T. A. M. Msagati, and B. B. Mamba, "Ferrite nanoparticles: synthesis, characterisation and applications in electronic device," Materials Science and Engineering: B, vol. 215, pp. 37-55, 2017.

[3] R. R. Kanna et al., "Impact of lanthanum on structural, optical, dielectric and magnetic properties of $\mathrm{Mn}_{1-x} \mathrm{Cu}_{x} \mathrm{Fe}_{1} .85 \mathrm{La} 0$. $15 \mathrm{O}_{4}$ spinel nanoferrites," Ceramics International, vol. 43, no. 17, pp. 15868-15879, 2017.

[4] M. Ayub, I. H. Gul, K. Nawaz, and K. Yaqoob, "Effect of rare earth and transition metal La-Mn substitution on electrical properties of co-precipitated M-type Ba-ferrites nanoparticles," Journal of Rare Earths, vol. 37, no. 2, pp. 193-197, 2019.

[5] M. A. Almessiere, F. Genc, H. Sozeri, A. Baykal, S. V. Trukhanov, and A. V. Trukhanov, "Influence of charge disproportionation on microwave characteristics of $\mathrm{Zn}-\mathrm{Nd}$ substituted Sr-hexaferrites," Journal of Materials Science: Materials in Electronics, vol. 30, no. 7, pp. 6776-6785, 2019.

[6] K. A. Korolev, C. Wu, Z. Yu, K. Sun, M. N. Afsar, and V. G. Harris, "Tunable ferromagnetic resonance in La-Co substituted barium hexaferrites at millimeter wave frequencies," AIP Advances, vol. 8, no. 5, Article ID 056440, 2018.

[7] A. R. A. Dairy, L. A. Al-Hmoud, and H. A. Khatatbeh, "Magnetic and structural properties of Barium Hexaferrite nanoparticles doped with Titanium," Symmetry, vol. 11, no. 6, p. 732, 2019.

[8] A. M. Awadallah and M. Sami, Effects of Preparation Conditions and Metal Ion Substitutions for Barium and Iron on the Properties of M-type Barium Hexaferrites, The University Of Jordan, Amman, Jordan, 2014.

[9] A.-F. Lehlooh, R. Alghazo, F. Rawwagah, A. Hammoudeh, and S. Mahmood, "Mössbauer spectroscopy study of Y-type Hexaferrite (Ba2Co2Fe12O22) prepared by the co-precipitation method," Hyperfine Interactions, vol. 241, no. 1, p. 21, 2020.

[10] C. C. Chauhan, A. R. Kagdi, R. B. Jotania et al., "Structural, magnetic and dielectric properties of $\mathrm{Co}-\mathrm{Zr}$ substituted M-type calcium hexagonal ferrite nanoparticles in the presence of $\alpha-\mathrm{Fe}_{2} \mathrm{O}_{3}$ phase," Ceramics International, vol. 44, no. 15 , pp. 17812-17823, 2018.

[11] I. A. Auwal, H. Güngüneş, A. Baykal, S. Güner, S. E. Shirsath, and M. Sertkol, "Structural, morphological, optical, cation distribution and Mössbauer analysis of $\mathrm{Bi}^{3+}$ substituted strontium hexaferrite," Ceramics International, vol. 42, no. 7, pp. 8627-8635, 2016.

[12] P. Behera and S. Ravi, "Effect of Ni doping on structural, magnetic and dielectric properties of M-type barium hexaferrite," Solid State Sciences, vol. 89, pp. 139-149, 2019.

[13] D. Suzuki, N. Sakamoto, K. Shinozaki, H. Suzuki, and N. Wakiya, "Magnetic field effects during deposition on crystal structure and magnetic properties of $\mathrm{BaFe}_{12} \mathrm{O}_{19}$ thin films prepared using PLD in the magnetic field (dynamic aurora PLD)," Journal of the Ceramic Society of Japan, vol. 121, no. 1409 , pp. 45-48, 2013.

[14] F. B. Abdallah, A. Benali, M. Triki, E. Dhahri, K. Nomenyo, and G. Lerondel, "Investigation of structural, morphological, optical and electrical properties of double-doping Lanthanum ferrite," Journal of Materials Science: Materials in Electronics, vol. 30, no. 4, pp. 3349-3358, 2019. 